\title{
Klaus Friedrich, Gennady E. Zaikov, and A. K. Hughi (Eds): Materials Chemistry. A. Multidisciplinary Approach to Innovative Methods
}

\author{
Peter Myers ${ }^{1}$
}

(C) Springer-Verlag Berlin Heidelberg 2016

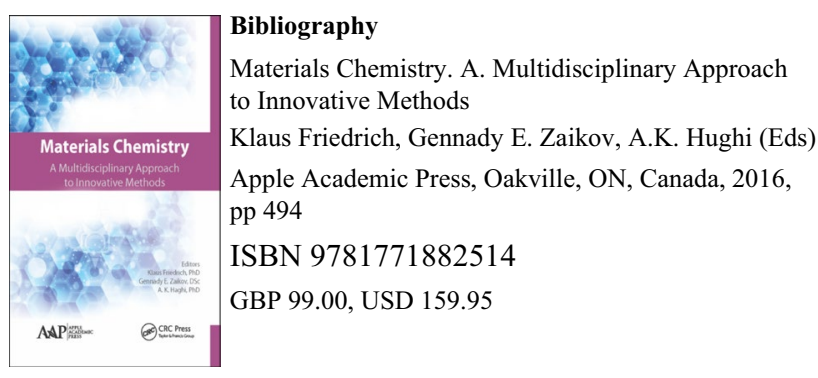

Working in a university department where the focus is on materials chemistry, I was particularly interested in reviewing this book. However, after reading past Chapter 6, my enthusiasm had disappeared. I had expected to read a general textbook on materials chemistry, but the chapters were very specific and very specialized in their subject matter. For example "Production of microtubes from chitosan solution in glycolic acid", "Cadmium and lead in acid sodpodzolic soils", and "Oxidation of apple pectin under the action of hydrogen peroxide" are not what I would call subjects of broad general interest.

The book is made up of 14 chapters that range from a mere six pages to one of 256 pages. In fact, this latter on "Trends in polymer chemistry" is really worthy of a book in its own right, and without it the rest of the book is nothing. The latest reference I found was to 2014 , and in a fastmoving field, this is already a long time.

In the Preface, the authors/editors talk of modern analytical techniques, but I was unable to find any. There was one reference to chromatography and two to IR, but nothing on MS, porosity determination or XRD. These are essential tools for materials scientists, but are missing from this book. I really have struggled to determine target audience for this book-the Preface says that it is for scientists and engineers. Yes, I think that is obvious, but to what subset(s) of these groups?

Should you buy this book? Look at the contents list of the 14 chapters. If one or more are of direct interest to you, then it may just be worth the price.
Peter Myers

Peter.Myers@liverpool.ac.uk

1 Department of Chemistry, University of Liverpool, Liverpool L69 3BX, UK 